\title{
Neuropsychological deficits in symptomatic minor head injury patients after concussion and mild concussion
}

\author{
Bruce E Leininger, Sandy E Gramling, Albert D Farrell, Jeffrey S Kreutzer, \\ Edward A Peck III
}

\begin{abstract}
Recent studies have concluded that most individuals who sustain minor head injury are free of persistent neuropsychological dysfunction. Nevertheless, a subgroup of patients experience continuing post-concussive difficulties and neuropsychological deficits. This study examined 53 symptomatic minor head injury patients referred for neuropsychological evaluation between one and 22 months after injury. These individuals performed significantly poorer than uninjured controls on four of eight neuropsychological tests. Patients who lost consciousness during injury obtained test scores similar to persons who experienced disorientation or confusion but no loss of consciousness. The results indicate that minor head injury patients who report post-concussive symptoms possess measurable neuropsychological deficits and the severity of these deficits is independent of neurological status immediately following injury.
\end{abstract}

Several recent controlled studies that examined consecutive admissions have yielded little evidence of neuropsychological deficits in most minor head injury patients one month post-injury. ${ }^{1-3}$ However, some patients report persisting post concussive symptoms and difficulty returning to work. ${ }^{4-7}$ Moreover, neuropsychological deficits have been observed in minor head injury patients three months to three years post injury. ${ }^{7-11}$ Although the great majority of minor head injury patients may not suffer enduring neuropsychological dysfunction, there is convincing evidence that a subgroup of individuals are clearly affected.

The last few years have witnessed continuing controversy over the incidence and duration of minor head injury and resulting cognitive impairment. Unfortunately, research has not examined other important issues such as the relative impact of loss of consciousness on the development of neuropsychological dysfunction after minor head injury. Emergency medical personnel routinely investigate and report whether head injury patients sustain loss of consciousness and presumably make inferences about the severity of injury. Information concerning loss of consciousness may be relevant in assessment and treatment decisions yet provide little insight into whether the patient is at greater or reduced risk for neuropsychological consequences.

This study examined whether minor head injuries accompanied by a loss of consciousness produce similar neuropsychological consequences to injuries that result in dazing but no loss of consciousness. The current study contains a number of important features: 1) only individuals who reported ongoing post concussive symptoms ${ }^{4}$ at one or more months post injury were examined; 2) patients with an antecedent history of significant head trauma, substance abuse, or low academic achievement were excluded; 3) practice effects were avoided by testing patients and control volunteers only once.

\section{Method \\ Subjects}

Data were obtained for 53 patients with minor head injury. The majority $(\mathbf{N}=31)$ had sustained a brief loss of consciousness, or "concussion." The remaining 22 patients experienced dazing injuries (such as, acute disorientation or confusion with or without perceptible amnesia and no loss of consciousness) more formally known as "mild concussion". ${ }^{12}$ Participants were seen for neuropsychological assessment at an outpatient neuropsychology private practice or outpatient rehabilitation medicine clinic. Head injury patients met the following research diagnostic criteria: a) history of head impact accompanied by acute confusion or disorientation, or traumatic loss of consciousness lasting 20 minutes or less; b) Glasgow Coma Score (when available) of 13-15 upon hospital admission; and c) no deterioration in neurological status or neurosurgical intervention.

Mild Concussion Group: This group was $45 \%$ male, $55 \%$ female; $73 \%$ were white and $27 \%$ black and included those with 11-20 years of education. Only one subject in this group was not in full or part-time employment or attending school before injury. Ninety per cent were injured in motor vehicle accidents. Time elapsed between injury and testing ranged from 1-20 months and $59 \%$ were pursuing claims for compensation.

Concussion Group: This group was $40 \%$ male, $60 \%$ female; $77 \%$ were white and $23 \%$ black, and contained those with 10-20 years of education. All were employed or attending school before injury. Ninety four per cent were injured in motor vehicle accidents. Time between injury and testing ranged from 1-22 months and $81 \%$ were pursuing claims. 
Control Group: Twenty three control volunteers were selected for their similarity to the head injury patients on demographic and comparison variables. The control group consisted of friends and family members of head injury inpatients at the Medical College of Virginia, and students and employees of Virginia Commonwealth University. The control group was $35 \%$ male, $65 \%$ female, $83 \%$ white and $17 \%$ black. Age ranged from 19 to 60 years, and education from 11 to 21 years. All control group subjects were employed or attending school full-time when tested.

\section{Instruments}

Head injury and control subjects were administered the Vocabulary subtest from the Wechsler Adult Intelligence Scale-Revised

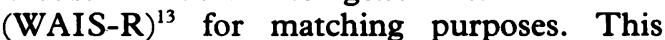
WAIS-R subtest correlates most highly with WAIS-R Full Scale $I^{13}$ and is relatively insensitive to acquired brain dysfunction. ${ }^{14}$ Eight neuropsychological tests were selected for their sensitivity to brain dysfunction. ${ }^{14}$ All tests used in this study are briefly described below.

WAIS-R Vocabulary ${ }^{13}$ Subjects provided definitions for words presented in order of increasing difficulty. Raw scores were converted to age scaled scores (maximum score = 19).

WAIS-R Digit Span: Digits Backwards ${ }^{13}$ Each subject was presented with progressively longer strings of digits and asked to repeat them in reverse order. The score was the longest string of digits correctly recalled in reverse order (maximum score $=8$ ).

Category Test ${ }^{15}$ The score for this test of reasoning ability was the total number of errors committed (maximum score $=208$ errors).

Trail Making Test: Part $B^{15}$ Subjects alternately connected numbered and lettered circles (that is, "1 $1-$ A $-2-$ B . . 13") on a sheet of paper. Time for successful completion was recorded (maximum score $=300$ seconds).

Auditory Verbal Learning Test ${ }^{16}$ Subjects attempted to learn a list of 15 common nouns presented over five trials. The score was the number of words correctly recalled across five trials (maximum score $=75$ ).

Complex Figure Test: Copy Trial ${ }^{17}$ Subjects copied a geometric figure which was scored for detail presence, location, and accuracy. ${ }^{18}$ Participants were not told they would later be asked to draw the figure from memory (maximum score $=36$ ).

Complex Figure Test: Memory Trial $^{17}$ Subjects drew the figure from memory three minutes after completing the copy trial. Drawings were scored as above (maximum score $=36$ ). Controlled Oral Word Association ${ }^{19}$ Subjects were asked to generate words that began with a consonant supplied by the examiner. Three trials were administered, each trial lasting 60 seconds. The score was the total words produced for the three trials adding standard corrections for age and education (no maximum score).

Paced Auditory Serial Addition Task-Revised $(P A S A T-R)^{20}$ This revised version of the PASAT $^{21}$ was originally adapted for use in the National Traumatic Coma Data Bank. ${ }^{22}$ Subjects were asked to add 26 successive digits in four trials consisting of $2 \cdot 8,2 \cdot 4,2 \cdot 0$, and 1.6 second intrastimulus intervals. The total number correct across the four trials was recorded (maximum score $=100$ ).

\section{Procedure}

Demographic information and test scores on the eight selected neuropsychological variables were gathered from patient assessment records. In addition, medical information documenting each patient's level of consciousness immediately following injury was used to assign subjects to the appropriate concussion group. In a few instances when objective information was unavailable, patients were assigned to either concussion group only when fully certain they had or had not sustained a complete loss of consciousness.

Control subjects were administered the neuropsychological test battery using standard administration and scoring procedures. The test battery was administered in incomplete counterbalanced order.

\section{Results}

Demographic and matching variables

Analyses conducted on demographic and matching variables revealed that head injury and control groups were similar in years of age, education, and WAIS-R Vocabulary score (table 1). These variables suggest that the groups had a similar ability to perform the neuropsychological battery barring the possibility of acquired brain dysfunction in the patient sample. Concussion and mild concussion subjects were comparable in age, education, WAIS-R Vocabulary score, and time elapsed between injury and testing.

Comparisons of neuropsychological data Multivariate analysis of variance was not used since listwise deletion of subjects with missing

Table 1 Group comparisons on demographic and matching variables

\begin{tabular}{|c|c|c|c|c|c|c|c|c|}
\hline Variables & $\begin{array}{l}\text { Mild } \\
\text { Concussion } \\
(N=22) \\
M\end{array}$ & $(S D)$ & $\begin{array}{l}\text { Concussion } \\
(N=31) \\
M\end{array}$ & $(S D)$ & $\begin{array}{l}\text { Control } \\
(N=23) \\
M\end{array}$ & $(S D)$ & $C_{1}$ & $C_{2}{ }^{b}$ \\
\hline $\begin{array}{l}\text { Age } \\
\text { Years of education } \\
\text { WAIS-R Vocabulary } \\
\text { Months since injury }\end{array}$ & $\begin{array}{r}30 \cdot 7 \\
13 \cdot 5 \\
9 \cdot 7 \\
6 \cdot 1\end{array}$ & $\begin{array}{r}(13 \cdot 6) \\
(2 \cdot 5) \\
(2 \cdot 7) \\
(6 \cdot 1)\end{array}$ & $\begin{array}{r}32 \cdot 9 \\
13 \cdot 7 \\
10 \cdot 5 \\
8 \cdot 4\end{array}$ & $\begin{array}{r}(10 \cdot 8) \\
(2 \cdot 8) \\
(3 \cdot 2) \\
(6 \cdot 7)\end{array}$ & $\begin{array}{l}32 \cdot 7 \\
14 \cdot 3 \\
10 \cdot 6\end{array}$ & $\begin{array}{r}(11 \cdot 8) \\
(2 \cdot 3) \\
(2 \cdot 3)\end{array}$ & $\begin{array}{l}0.774 \\
1.137 \\
0.673\end{array}$ & $\begin{array}{l}0.510 \\
0.340 \\
1.059 \\
1.259\end{array}$ \\
\hline
\end{tabular}

Note: ${ }^{2} \mathrm{~L}$ inear contrasts comparing head injury and control subjects, $t(2 / 73)$. ${ }^{b} \mathrm{~L}$ inear contrasts comparing mild concussion and concussion groups, $\mathrm{t}(1 / 51)$. 
Table 2 Comparisons of neuropsychological test scores by group

\begin{tabular}{|c|c|c|c|c|c|c|c|c|}
\hline Variables & $\begin{array}{l}\text { Mild } \\
\text { Concussion } \\
\text { M }\end{array}$ & $S D$ & $\begin{array}{l}\text { Concussion } \\
M\end{array}$ & $S D$ & $\begin{array}{l}\text { Control } \\
M\end{array}$ & $S D$ & $C_{1}^{2}$ & $C_{2}{ }^{b}$ \\
\hline $\begin{array}{l}\text { Category Test } \\
\text { Complex Figure: Copy } \\
\text { PASAT-R } \\
\text { Auditory Verbal Learning Test } \\
\text { Complex Figure: Memory } \\
\text { Controlled Oral Word Association } \\
\text { Trail Making Part B } \\
\text { Digits Backwards }\end{array}$ & \begin{tabular}{r|}
$49 \cdot 5$ \\
$32 \cdot 3$ \\
$78 \cdot 9$ \\
$54 \cdot 4$ \\
$18 \cdot 2$ \\
$37 \cdot 6$ \\
$65 \cdot 6$ \\
$5 \cdot 3$
\end{tabular} & $\begin{array}{r}(29 \cdot 7) \\
(4 \cdot 0) \\
(12 \cdot 6) \\
(8 \cdot 3) \\
(8 \cdot 1) \\
(9 \cdot 1) \\
(23 \cdot 6) \\
(1 \cdot 4)\end{array}$ & $\begin{array}{r}49 \cdot 3 \\
32 \cdot 0 \\
73 \cdot 1 \\
49 \cdot 2 \\
18 \cdot 6 \\
39 \cdot 5 \\
82 \cdot 1 \\
4 \cdot 8\end{array}$ & $\begin{array}{r}(27 \cdot 4) \\
(3 \cdot 3) \\
(18 \cdot 9) \\
(10 \cdot 9) \\
(6 \cdot 7) \\
(9 \cdot 6) \\
(54 \cdot 5) \\
(1 \cdot 4)\end{array}$ & $\begin{array}{r}25 \cdot 3 \\
34 \cdot 4 \\
86 \cdot 1 \\
57 \cdot 7 \\
22 \cdot 1 \\
43 \cdot 3 \\
57 \cdot 7 \\
5 \cdot 1\end{array}$ & $\begin{array}{r}(19 \cdot 0) \\
(1 \cdot 2) \\
(11 \cdot 2) \\
(8 \cdot 7) \\
(6 \cdot 5) \\
(9 \cdot 4) \\
(22 \cdot 1) \\
(1 \cdot 4)\end{array}$ & $\begin{aligned}-3 \cdot 640^{\star} \dagger \\
2 \cdot 854^{\star} \dagger \\
2 \cdot 650^{\star} \dagger \\
2 \cdot 407^{\star} \dagger \\
2 \cdot 077^{\dagger} \\
1 \cdot 967 \\
-1 \cdot 632 \\
0 \cdot 082\end{aligned}$ & $\begin{array}{r}-0.036 \\
-0.351 \\
-1 \cdot 319 \\
-1 \cdot 869 \\
0 \cdot 204 \\
0.690 \\
1 \cdot 466 \\
-1 \cdot 162\end{array}$ \\
\hline
\end{tabular}

Note: Higher scores are preferable on all measures except for the Category Test and Trail Making Part B. "Linear contrasts comparing head injury and control subjects. 'Linear contrasts comparing mild concussion and concussion patients. Linear contrasts were calculated with 65-72 degrees of freedom because of missing data. $t p_{t}<0.05$. ${ }^{\star} p_{f} w<0.10 ; p_{t}<0.0125$ at stage 1 , $p_{\mathrm{t}}<0.02$ at stage 2 using a multistage Bonferroni procedure.

data would have attentuated the head injury sample size. Consequently, the neuropsychological data were analysed using analyses of variance with two linear contrasts per variable, with the conservative multistage Bonferroni procedure ${ }^{23}$ to control for multiple comparisons. Table 2 displays means and standard deviations on the eight neuropsychological variables by group. The $t$ values are presented for linear contrasts comparing head injury patients and controls $\left(C_{1}\right)$, and concussion and mild concussion groups $\left(\mathrm{C}_{2}\right)$.

Minor head injury patients scored significantly poorer $(p<0.05)$ than control subjects on five of eight neuropsychological tests including the Category Test, PASAT-R, Auditory Verbal Learning Test, and both copy and memory trials of the Complex Figure Test. Differences on four tests (that is, all but the memory trial of the Complex Figure Test) remained significant with the multistage Bonferroni procedure. The Bonferroni procedure employed a familywise error rate, pfw, of $0 \cdot 10$ (the procedure was completed after the second stage; the per test significance rate for the first stage and second stage were $p<0.0125$ and $p<0.02$, respectively).

The above series of analyses revealed unequivocal evidence of neuropsychological impairment in the minor head injury patients, thus providing a rationale for comparing the performance of concussion and mild concussion patients. Linear contrasts were computed between the concussion groups on the eight neuropsychological variables. No significant differences between groups were obtained on any of the tests.

Two additional series of analyses examined the potential influence of litigation status and post-concussive symptom duration on neuropsychological functioning. Comparisons of neuropsychological data for patients pursuing litigation $(\mathrm{N}=39)$ versus not pursuing litigation $(\mathrm{N}=14)$ revealed a significant difference $(p<0.05)$ on the copy portion of the Complex Figure Test. This difference failed to remain significant with the Bonferroni correction procedure. The remaining comparisons did not exceed a significance level of $p=0.45$. No significant differences in neuropsychological performance were observed between patients tested within three months of injury $(\mathrm{N}=22)$ and patients tested beyond three months of injury $(\mathrm{N}=31)$.

\section{Discussion}

Minor head injury has received much attention since the Rimel et al study alerted health professionals to the high morbidity associated with these injuries. Subsequent research has challenged the Rimel et al findings, in particular, the incidence and duration of neuropsychological dysfunction among minor head injury patients. ${ }^{1-3}$ These studies propose that enduring neuropsychological debility after minor head insult is the exception rather than the rule. Nevertheless, this study and others ${ }^{7-11}$ provide compelling evidence that some individuals experience persisting deficits. The results of the current study generalise most directly to the subgroup of minor head injury patients who report post-concussive symptoms one month post-injury and beyond. This study did not investigate the incidence or duration of neuropsychological dysfunction within the larger minor head injury population.

Symptomatic minor head injury patients in this study displayed significantly poorer performance than uninjured controls on several neuropsychological tests. Deficits were most evident on tests of reasoning, information processing, and verbal learning. Previous studies have reported similar neuropsychological deficits after minor head injury though the length of dysfunction remains controversial. ${ }^{1-37-1124}$ The patient group also performed significantly poorer than controls on a test which required the reproduction of a complex geometric design. Inefficient organisation, poor attention to detail, and faulty error recognition contributed to reduced scores more so than gross visuospatial or motor integration deficits.

The primary interest of this investigation was to explore whether injuries accompanied by a brief loss of consciousness result in poorer neuropsychological outcome than injuries not accompanied by loss of consciousness. Analyses compared the neuropsychological performance of concussion and mild concussion patients and revealed no evidence that injuries associated with a brief traumatic loss of consciousness were more debilitating than injuries initially associated with dazing but no formal loss of consciousness. There is no question that severe head injuries accompanied by extended unconsciousness and coma typically result in neuropsychological dysfunction, ${ }^{25}$ and are by definition typically more 
damaging than injuries associated with limited or no loss of consciousness. As far as minor head injuries are concerned, however, the occurrence or non-occurrence of a traumatic loss of consciousness does not seem to distinguish persons at greater or reduced risk for neuropsychological consequences.

Four factors are believed to have contributed to the magnitude of performance discrepancy between head injury patients and controls in this study relative to previous investigations. One, all patients were symptomatic at one month or more post-injury. Not all minor head injury patients suffer post-concussive symptoms, consequently, this sample may represent those individuals at greater risk for neuropsychological deficits. Two, nearly all of the patients in the present sample were injured in motor vehicle accidents which may possess greater opportunity for acceleration-deceleration injury than falls, sports injuries, and assaults. The percentage of motor vehicle accident victims in this study is considerably higher than that reported in most previous studies of minor head injury. Interestingly, a recent study ${ }^{10}$ that confined its focus to mild concussion patients injured in motor vehicle accidents reported evidence of neuropsychological impairment in patients one year post-injury and beyond. Three, this sample of patients may have displayed relatively higher levels of impairment than that found in most previous studies because subjects were injured during the third decade of life or later. While a mean age over 30 is not uncommon in minor head injury research, ${ }^{310}$ increasing age appears to be associated with poorer outcome. ${ }^{4610}$ Four, this study incorporated tests that were generally sensitive to the variety of cognitive deficits associated with minor head injury, and eliminated practice effects that could be of unequal magnitude for patients and controls. ${ }^{1}$

Minor head injury patients displayed certain difficulty with some tests and little difficulty with other tests relative to controls. Head injury patients and controls performed similarly on the digits backward tasks and mild concussion patients obtained a higher mean score than controls. Given these results, it is understandable that other studies ${ }^{13}$ which used simple digit repetition tasks did not detect impairment among their minor head injury subjects. There is no doubt that even the most sensitive neuropsychological tests do not tap some of the subtle processing deficits which result from minor head injury.

Two factors did not appear to influence the main findings. Although most head injury patients in the study were pursuing claims for compensation, there was no conclusive evidence that litigating patients obtained different scores than non-litigating patients. These results bolster the conclusion that the differences obtained between minor head injury patients and controls are a genuine consequence of traumatic brain injury. A second factor which also did not significantly influence the results was the point during recovery at which patients were tested. Patients with post-concussive symptoms tested within three months of injury obtained test scores similar to symptomatic patients tested after three months of injury. This suggests that minor head injuries are not always innocuous, fully reversible conditions which resolve within days or a few weeks of injury. Rather, some patients appear to suffer enduring neuropsychological impairments.

Clinicians are encouraged to be sensitive to the potentially serious consequences of minor head injury even in cases where no loss of consciousness is reported. Neuropsychological evaluation of patients with post-concussive symptoms will often provide justification for many complaints which might be erroneously attributed to neuroticism or greed. Test results are also useful in developing individualised rehabilitation programmes and determining when individuals are prepared to resume vocational or academic routines. Researchers are encouraged to shift their attention from description of typical recovery to early identification and rehabilitation of affected individuals.

1 Levin HS, Mattis S, Ruff RM, et al. Neurobehavioral outcome following minor head injury: a three center study. 1987;66:234-43.

2 Dikmen S, McLean A, Temkin N. Neuropsychological and psychosocial consequences of minor head injury. J Neurol psychosocial consequences of minor head
Neurosurg Psychiatry 1986;49:1227-32.

3 Gentilini M, Nichelli P, Schoenhuber R, et al. Neuropsychological evaluation of mild head injury. J Neurol Neurosurg Psychiatry 1985;48:137-40.

4 Rutherford WH, Merrett JD, McDonald JR. Sequelae of concussion caused by minor head injuries. Lancet 1977;i:1-4.

5 Rutherford WH, Merrett JD, McDonald JR. Symptoms at one year following concussion from minor head injuries. Injury 1979;10:225-30.

6 Wrightson P, Gronwall D. Time off work and symptoms after minor head injury. Injury 1981;12:445-54.

7 Rimel RW, Giordani B, Barth JT, Boll TJ, Jane JA Disability caused by minor head injury. Neurosurg 1981;9:221-8.

8 Barth JT, Macciocchi SN, Giordani B, et al. Neuropsychological sequelae of minor head injury. Neurosurgery 1983;13:529-32.

9 Hugenholtz H, Stuss DT, Stethem LL, Richard MT. How long does it take to recover from a mild concussion? Neurosurgery 1988;22:853-8.

10 Yarnell PR, Rossie GV. Minor whiplash head injury with major debilitation. Brain Injury 1988;2:255-8.

1 Ewing R, McCarthy D, Gronwall D, Wrightson P. Persisting effects of minor head injury observable during hypoxic stress. J Clin Neuropsychol 1980;2:147-55.

2 Gennarelli TA. Cerebral concussion and diffuse brain injuries. In Cooper PR, ed. Head Injury. Baltimore: Williams and Wilkins, 1982:83-98.

13 Wechsler D. Wechsler Adult Intelligence Scale-Revised, Manual. New York: Psychological Corporation, 1981.

14 Lezak M. Neuropsychological Assessment (2nd ed) New York: Oxford University Press, 1983.

15 Reitan RM, Davison LA (eds). Clinical Neuropsychology. Current Status and Applications. Washington DC: Winston and Sons, 1974.

16 Rey A. L'examen Clinique en Psychologie. Paris: Presses Universitaries de France, 1964

17 Rey A. L'examen psychologique dans les cas d'encephalopathie traumatique. Archives de Psychologie 1941;28:286-340.

18 Taylor EM. The Appraisal of Children with Cerebral Deficits. Cambridge, Mass: Harvard University Press, 1959.

19 Benton AL, Hamsher K. Multilingual Aphasia Examination. Iowa City: University of Iowa, 1976

20 Levin HS. The Paced Auditory Serial Addition TaskRevised. University Of Texas at Galveston, 1983, (unpublished).

21 Gronwall D. Paced auditory serial-addition task: A measure of recovery from concussion. Perceptual and Motor Skills 1977;44:367-73.

22 Marshall LF, Becker DP, Bowers SA, et al. The national traumatic coma data bank. Part 1: Design, purpose, goals, and results. J Neusosurg 1983;59:276-84.

23 Larzelere RE, Mulaik SA. Single-sample tests for many correlations. Psychological Bulletin 1977;84:557-69.

24 Gronwall $D$, Wrightson $P$. Delayed recovery of intellectual function after minor head injury. Lancet 1974;ii:605-9.

25 Levin HS, Grossman RG, Rose JE, Teasdale G. Long-term neuropsychological outcome of closed head injury. $J$ Neurosurg 1979;50:412-22.

This study was originally submitted by the first author as part of his MSc in Psychology at Virginia Commonwealth University. He is grateful to the co-authors and Dr Kent G Bailey for their 